\title{
Occupational stress and stressors experienced by the newly practicing nurses in intensive care units
}

\author{
Mona Abdel Wareth*1,2, Sameh Eltaybani ${ }^{1,3}$ \\ ${ }^{1}$ Department of Critical Care and Emergency Nursing, Faculty of Nursing, University of Alexandria, Alexandria, Egypt \\ ${ }^{2}$ Department of Medical Surgical Nursing, Faculty of Nursing, Princess Nourah bint Abdulrahman University, Riyadh, Kingdom \\ of Saudi Arabia \\ ${ }^{3}$ Department of Palliative Care Nursing, Division of Health Science and Nursing, Graduate School of Medicine, The University of \\ Tokyo, Tokyo, Japan
}

Received: September 18, 2018

Accepted: October 18, 2018

Online Published: November 8, 2018

DOI: $10.5430 /$ jnep.v9n3p7

URL: https://doi.org/10.5430/jnep.v9n3p7

\begin{abstract}
Background and objective: Nurses working in critical care units face occupational stress particularly in the first six months of their practice; however, research on nurses' perceived stress during this period is extremely limited. The aim of the study was to assess occupational stress and stressors experienced by the newly practicing nurses in intensive care units (ICUs).

Methods: Design: A cross-sectional, descriptive, quantitative research design. Settings: Four ICUs in a university hospital in Alexandria governorate, Egypt. Participants: A convenient sample of 100 intern nurses who had their first clinical work experience in ICU during the internship. Method: This is a cross-sectional, descriptive, quantitative survey study conducted in four ICUs in Alexandria university hospital, Egypt. A questionnaire sheet consisting of two parts was used to collect data. Part one is the nursing stress scale and part two is the respondents' socio-demographic and work-related data. Descriptive and bivariate statistical analyses were used to describe study variables and their associations.

Results: All of the studied newly practicing nurses in ICUs experienced either moderate (43\%) or high (57\%) stress level. There are differences between the perceived stress reported by the studied nurses according to their characteristics (e.g., sex, marital status, having private work). These differences were not statistically significant. Death and dying, workload, and inadequate preparation are the top ranked stressors; average scores are 2.22, 2.20, and 2.13 respectively. In their first two months of experiences, nurses perceived inadequate preparation and death and dying as the highest stressors. This ranking differs among nurses with 3-4 months of experience and nurses with 5-6 months of experience.

Conclusions and recommendations: Newly practicing nurses in ICUs face a significant level of stress. Death and dying, workload, and inadequate preparation are the top ranked stressors. Recommendations: Stress-management program must be initiated for new practicing nurses in ICU. Death and dying in ICU are highly needed topics to be embedded into nursing curriculum. Strategies to help graduate nurses cope must be implemented.
\end{abstract}

Key Words: Egypt, Newly practicing nurses, Novice nurses, Occupational stress, Stress, ICU

\section{INTRODUCTION}

Stress is an occupational hazard that is defined as an internal cue in the physical, social, or psychological environment that threatens the equilibrium of an individual. ${ }^{[1,2]}$ Occupational or professional stress is a pattern of emotional, cognitive, behavioral, and physiological reactions to adverse and harmful

\footnotetext{
* Correspondence: Mona Abdel Wareth; Email: msahmed@pnu.edu.sa; Address: Department of Critical Care and Emergency Nursing, Faculty of Nursing, University of Alexandria, Egypt.
}

Published by Sciedu Press 
aspects of job-related factors, including work content, organization, and the environment. ${ }^{[3,4]}$ It occurs when working environment demands exceed the workers' coping capacities. ${ }^{[5,6]}$ In nursing, stress is attributed to the physical efforts, suffering and demands of patients and families, work load, including extra working time, multiple duties in a limited time and limited rest time, interpersonal relationships, and other burdens related to nurses' work. ${ }^{[5,7,8]}$

Working in critical care units is extremely challenging. ${ }^{[9]}$ Critically ill patients have a higher acuity of illness than other patients in medical/surgical units. ${ }^{[10]}$ It is a must for critical care nurses to have comprehensive knowledge of emergency management, diagnoses, monitoring in addition to proficient skills of assessment, problem solving, and decision-making. ${ }^{[11,12]}$ Occupational stress may significantly affect nurses' physical and psychological health. It increases the probability of anxiety, depression, cardiovascular, and locomotor diseases. These negatively affect nurses' quality of life. Occupational stress decreases compassion to patients, increases rate of errors, and decreases the quality of care $^{[5,13-16]}$ Therefore, numerous studies ${ }^{[5,6,8,14,17-20]}$ were concerned with nurses' occupational stress, stressors, and the related consequences.

Sarafis et al. ${ }^{[14]}$ studied 246 nurses from different educational categories to determine the relation between nurses' work stress and their caring behaviors and health-related quality of life. They reported that dealing with death, patients and families, conflict with managers and doubt about the treatment effects resulted in significantly higher stress. They also reported that occupational stress negatively affected nurses' health-related quality of life. In a multi-center study, ${ }^{[5]}$ critical care nurses rated situations concerning working environments either physical or psychological as the most stressful. Significant differences in the perception of stresses of particular stressors were observed with respect to psychosomatic manifestations and certain illnesses. A study by Shivaprasad ${ }^{[8]}$ revealed that $52 \%$ of the nurses had severe level of stress. Workload and patients and families, problems involving colleagues, death and dying, and problems concerning managers were the top causes of severe level of stress. Kamal and colleagues ${ }^{[19]}$ ranked patient's demands, family's complaints and workload as the most stressful categories. They also documented that critical care and emergency nurses experienced a high level of stress which resulted in low level of job satisfaction.

Nurse students are sheltered from stressful situations. They are not exposed to actually distressing requirements needed from the employed nursing staff. The transition from nursing student to practicing nurse is complex and challenging. ${ }^{[13,21]}$
The new graduates move on a continuum till they have advanced thinking and competency. ${ }^{[17]}$ New graduate nurses require 12 to 18 months to feel competent in ICU practices. ${ }^{[22]}$ Intern nurses are considered beginning level nurses or newly practicing nurses. They are unfamiliar and inexperienced in dealing with the complex working environment, especially those who do not have a private experience before internship. They lack awareness about specialized equipment functions and operation. In addition, they are lacking control over patient care tasks leading to emotional exhaustion and occupational stress. ${ }^{[23,24]}$ In Egypt, for example, where the current study was conducted, the internship program is a mandatory work-based program which allows graduates exposure to a variety of educational opportunities at clinical settings and assist the adjustment from students to registered nurses. To our knowledge, there are no published statistics regarding the Egyptian critical care nursing workforce. Nevertheless, as a result of some work-related legislations, hospital policies, and nursing shortage, it is not rare for intern nurses to be the main portion of the ICU nursing workforce specially during the evening and night shifts. ${ }^{[25]}$ This situation puts newly practicing nurses under considerable stress without enough supervision or support.

Researchers reported that the first 3 to 6 months of employment are the most stressful for nurses' career. ${ }^{[26-28]}$ This may be attributed to that, transition from study to work results in loss of the familiar setting and switching to a noticeably new culture. ${ }^{[29]}$ Yeh et al. ${ }^{[20]}$ documented that new nurse graduates perceived moderate job stress which significantly influenced their intention to quit. In addition, the national healthcare retention and registered nurses staffing report ${ }^{[30]}$ revealed that the turnover is $30 \%$ during the first year of registered nurses' employment. Though the importance of the beginning of the transmission period, many studies concerned with occupational stress either excluded or did not concern in specific the new practicing nurses (i.e., those who had less than 6 months experience). ${ }^{[5,7,19,31,32]}$ Hence, the current study is implemented to assess occupational stress and stressors experienced by the newly practicing nurses in ICUs.

\subsection{Aim of the study}

The aim of this study is to assess occupational stress and stressors experienced by the newly practicing nurses in ICUs.

\subsection{Research questions}

(1) What is the severity of occupational stress experienced by the newly practicing nurses in ICUs?

(2) What are the occupational stressors experienced by the newly practicing nurses in ICUs? 


\section{MeTHOD}

\subsection{Research design and sampling}

This is a cross-sectional, descriptive, quantitative survey study was conducted in four ICUs in a university hospital in Alexandria, Egypt with a total bed capacity of 42 beds (i.e., 17, 9, 8, and 8 beds). A convenience sample of newly practicing nurses in ICUs (100 intern nurses) was included in this study. Included intern nurses had their first clinical work experience in the ICU during the internship and their experience is ranging from one month to six months. Intern nurses who had a previous work experience in ICU before internship were excluded from the study.

\subsection{Instrument}

To assess occupational stress and stressors experienced by the newly practicing nurses in intensive care units (ICUs), the English version of Nursing Stress Scale (NSS) was adopted. This scale was developed by Toft and Anderson. ${ }^{[1]}$ It is composed of 34 items clustered into seven categories; death and dying patients ( 7 items), conflict with physicians ( 5 items), inadequate preparation ( 3 items), lack of staff support ( 3 items), conflict with other nurses (5 items), workload (6 items), and uncertainty concerning treatment (5 items). A 4-point Likert scale was used to elicit the frequency of nurses' experienced work stressors: never (0), occasionally (1), frequently (2), very frequently (3). The severity of stress is determined as follows: low (0-34), moderate (35-68), High (69-102) based on the total score allotted for the seven categories. Internal consistency reliability of NSS in this study was assessed using Cronbach's coefficient alpha (0.79). In addition to the NSS scale, a supplementary questionnaire was used to obtain socio-demographic data (gender, age, marital status), and work related data (daily work hours, the presence of an extra private work) from the study participants.

\subsection{Data collection}

A permission to conduct this study was obtained from hospital responsible authorities after explaining the aim of the work. An informed consent was obtained from included nurses after explaining the aim of this study. A pilot study was conducted on 10 intern nurses who are placed at the previously mentioned ICUs. To assess the clarity and applicability of the study tool. The questionnaire sheet was introduced to the studied nurses at their break time in the nurses' room. The questionnaire sheets were collected immediately after completion of the same shift. Data collection was done from May to October 2016.

\subsection{Statistical analysis}

First, descriptive statistical analysis for all study variables was conducted. Second, researchers performed bivariate anal- yses to examine the association between independent variables (i.e., sociodemographic and work-related variables) and the stress level (NSS total score) using independent sample $t$-test (for two level categorical variables), one-way ANOVA (for three level categorical variables) and Pearson productmoment correlation (for continuous variables). Third, we compared between levels of stress and stressors in three groups: nurses by 1-2 months of experience, nurses by 3-4 months of experience, and nurses with 5-6 months of experience. Since items per each stressor in the NSS are not the same, we used the average score to allow their comparability (i.e., total subscale score divided by the number of items of the subscale). All statistics were conducted using SPSS version 20. All reported $p$ values are two tailed and the .05 level was used to test statistical significance.

\subsection{Ethical consideration}

The current study was approved by the research ethics committee of the faculty of nursing, Alexandria University, Egypt. Participation in this study was voluntary. Participants were informed of their right to withdraw from the study at any time. An informed consent was obtained from each of the included nurses after explaining the aim of this study. Nurses' confidentiality, anonymity, and privacy were ensured during the study.

\section{RESUlts}

Table 1 shows that $57 \%$ of the studied intern nurses are females, most of them (82\%) are single, $63 \%$ are working for 6 to 12 hours daily, $63 \%$ do not have additional private work, $55 \%$ have 3 to 4 months ICU experience. All of the studied nurses are experiencing either moderate or high stress; $43 \%$ and $57 \%$ respectively. The percent of female nurses who had severe stress is $64.9 \%$. It is higher than that $(35.1 \%$ ) for male nurses who have the same level of stress. More than half of single nurses $(59.8 \%)$ have severe stress, which is higher than that (44.4\%) for married nurses.

More than half $(58.7 \%)$ of nurses who are working from 6 to 12 hours daily have severe stress, which is higher than that $(54.1 \%)$ for nurses who are working from 12 to 18 hours daily. The percent of nurses who have private work and have severe stress is $54.1 \%$. It is lower than that $(58.7 \%)$ for nurses who do not have a private work. A large percent $(73.7 \%)$ of nurses who have work experience from 5 to 6 months have severe stress compared to that $(54.5 \%)$ of nurses who have work experience from 3 to 4 months and that $(50.0 \%)$ for nurses who have work experience from 1 to 2 months. All differences were statistically insignificant. 
Table 1. The association between stress level experienced by the studied nurses and their characteristics

\begin{tabular}{|c|c|c|c|c|c|c|}
\hline \multirow{3}{*}{\multicolumn{2}{|c|}{ Participants' characteristics }} & \multirow{3}{*}{$\begin{array}{l}\text { Total } \\
\text { N = 100 } \\
\text { No. }(\%)\end{array}$} & \multicolumn{4}{|c|}{ Nursing Stress Scale } \\
\hline & & & \multirow{2}{*}{$\begin{array}{l}\text { Total } \\
71.9 \pm 13.3\end{array}$} & \multirow{2}{*}{$\begin{array}{l}\text { Low } \\
00(00 \%)\end{array}$} & \multirow{2}{*}{$\begin{array}{l}\text { Moderate } \\
43(43 \%)\end{array}$} & \multirow{2}{*}{$\begin{array}{l}\text { High } \\
57(57 \%)\end{array}$} \\
\hline & & & & & & \\
\hline \multirow{3}{*}{$\begin{array}{l}\text { Sex } \\
p \text { value }\end{array}$} & Female & 57 (57.0\%) & $73.2 \pm 13.5$ & --- & 20 (35.1\%) & 37 (64.9\%) \\
\hline & Male & 43 (43.0\%) & $70.2 \pm 12.9$ & --- & 23 (53.5\%) & 20 (46.5\%) \\
\hline & & ----- & .720 & .071 & & \\
\hline \multirow{3}{*}{$\begin{array}{l}\text { Marital status } \\
p \text { value }\end{array}$} & Single & $81(82.0 \%)$ & $72.4 \pm 13.7$ & --- & $33(40.2 \%)$ & 49 (59.8\%) \\
\hline & Married & $18(18.0 \%)$ & $69.8 \pm 11.3$ & --- & $10(55.6 \%)$ & $8(44.4 \%)$ \\
\hline & & ----- & .205 & .296 & & \\
\hline \multirow{2}{*}{ Daily work hours } & 6-12 hours & $63(63.0 \%)$ & $72.6 \pm 13.0$ & --- & $26(41.3 \%)$ & 37 (58.7\%) \\
\hline & 12-18 hours & 37 (37.0\%) & $70.8 \pm 13.9$ & --- & 17 (45.9\%) & 20 (54.1\%) \\
\hline$p$ value & & ----- & .821 & .680 & & \\
\hline \multirow{2}{*}{ Private work } & Yes & 37 (37\%) & $70.7 \pm 13.9$ & --- & 17 (45.9\%) & $20(54.1 \%)$ \\
\hline & No & $63(63 \%)$ & $72.6 \pm 13.0$ & --- & $26(41.3 \%)$ & 37 (58.7\%) \\
\hline \multirow[t]{2}{*}{$p$ value } & & ----- & .785 & .680 & & \\
\hline & $1-2 \mathrm{~m}$. & $26(26.0 \%)$ & $70.9 \pm 16.5$ & --- & $13(50.0 \%)$ & $13(50.0 \%)$ \\
\hline \multirow[t]{2}{*}{ ICU experience } & 3-4 m. & 55 (55.0\%) & $71.6 \pm 12.7$ & --- & 25 (45.5\%) & $30(54.5 \%)$ \\
\hline & 5-6 m. & 19 (19.0\%) & $74.1 \pm 10.1$ & --- & $5(26.3 \%)$ & $14(73.7 \%)$ \\
\hline$p$ value & & ----- & .731 & .257 & & \\
\hline
\end{tabular}

Concerning the overall ranking of stressors, Table 2 reveals that death and dying, increased workload, inadequate preparation are the top 3 ranked stressors, respectively. On the contrary, the least ranked stressor is the conflict with other nurses. Regarding the ranking of stressors according to the duration of nurses' experience in the ICU, inadequate preparation is the top stressor for nurses who had 1 to 2 months experience in the ICU followed by death and dying and lack of support, respectively. The workload is the top stressor for nurses who had 3 to 4 months experience followed by death and dying and conflict with physicians, respectively. For nurses who had 5 to 6 months experience, death and dying is the atop ranked stressor followed by workload and lack of support respectively.

Table 2. Distribution and ranking of stressors experienced by the studied nurses

\begin{tabular}{|c|c|c|c|c|c|c|c|c|c|c|}
\hline \multirow[t]{3}{*}{ Nursing stressors } & \multirow{3}{*}{$\begin{array}{l}\text { No. of } \\
\text { items }\end{array}$} & \multirow[t]{3}{*}{ Mean \pm SD } & \multicolumn{8}{|c|}{ Stressors ranking * } \\
\hline & & & \multicolumn{2}{|c|}{ Overall } & \multicolumn{2}{|c|}{ First 2 months } & \multicolumn{2}{|c|}{ Second 2 months } & \multicolumn{2}{|c|}{ Third 2 months } \\
\hline & & & \multicolumn{2}{|c|}{ Average (Rank) } & \multicolumn{2}{|c|}{ Average (Rank) } & \multicolumn{2}{|c|}{ Average (Rank) } & \multicolumn{2}{|c|}{ Average (Rank) } \\
\hline Death and dying & 7 & $15.6 \pm 3.6$ & 2.22 & (1) & 2.21 & (2) & 2.21 & (2) & 2.27 & (1) \\
\hline Conflict with physicians & 5 & $10.2 \pm 2.7$ & 2.05 & (6) & 2.039 & (6) & 2.08 & (3) & 1.96 & (7) \\
\hline Inadequate preparation & 3 & $6.4 \pm 1.8$ & 2.13 & (3) & 2.28 & (1) & 2.042 & (5) & 2.19 & (5) \\
\hline Lack of support & 3 & $6.3 \pm 1.8$ & 2.09 & (4) & 2.10 & (3) & 2.03 & (6) & 2.25 & (3) \\
\hline Conflict with other nurses & 5 & $9.8 \pm 3.0$ & 1.98 & (7) & 1.92 & (7) & 1.95 & (7) & 2.11 & (6) \\
\hline Workload & 6 & $13.2 \pm 3.6$ & 2.20 & $(2)$ & 2.045 & (5) & 2.26 & (1) & 2.26 & (2) \\
\hline Uncertainty concerning treatment & 5 & $10.4 \pm 2.8$ & 2.07 & (5) & 2.05 & (4) & 2.043 & (4) & 2.20 & (4) \\
\hline
\end{tabular}

* Ranking is based on the average score of each stressor category because of the unequal distribution of items among categories.

Table 3 shows that the mean scores for all stressor categories among female intern nurses are higher than that for male intern nurses. Nurses who are working 6 to 12 hours daily and those who do not have private work have higher mean scores for death and dying, inadequate preparation, lack of support, uncertainty concerning treatment. Nurses who are working 12 to 18 hours daily and those who have additional private nursing work have higher mean scores for conflict 
with physicians and conflict with other nurses. Nurses at the beginning of their experience (i.e., 1-2 months) have higher mean scores for inadequate preparation, conflict with physicians, and uncertainty concerning treatment, while nurses with prolonged experience have higher mean scores for death and dying, lack of support, conflict with other nurses. The difference between mean scores of stressor categories are statistically insignificant.

Table 3. The association between nurses characteristics and stressors

\begin{tabular}{|c|c|c|c|c|c|c|c|c|}
\hline \multirow[t]{2}{*}{$\begin{array}{l}\text { Participants' } \\
\text { characteristics }\end{array}$} & & $\begin{array}{l}\text { Death and } \\
\text { dying }\end{array}$ & $\begin{array}{l}\text { Conflict } \\
\text { with } \\
\text { physicians }\end{array}$ & $\begin{array}{l}\text { Inadequate } \\
\text { preparation }\end{array}$ & $\begin{array}{l}\text { Lack of } \\
\text { support }\end{array}$ & $\begin{array}{l}\text { Conflict } \\
\text { with other } \\
\text { nurses }\end{array}$ & Workload & $\begin{array}{l}\text { Uncertainty } \\
\text { concerning } \\
\text { treatment }\end{array}$ \\
\hline & & Mean \pm SD & Mean \pm SD & Mean \pm SD & Mean \pm SD & Mean \pm SD & Mean \pm SD & Mean \pm SD \\
\hline \multirow{2}{*}{ Sex } & Female & $15.6 \pm 3.6$ & $10.5 \pm 2.4$ & $6.3 \pm 1.9$ & $6.5 \pm 1.9$ & $10.2 \pm 3.0$ & $13.4 \pm 3.4$ & $10.7 \pm 2.9$ \\
\hline & Male & $15.6 \pm 3.8$ & $9.9 \pm 2.9$ & $6.4 \pm 1.7$ & $6.0 \pm 1.7$ & $9.3 \pm 3.0$ & $13.0 \pm 3.8$ & $10.0 \pm 2.6$ \\
\hline$p$ value & & .597 & .241 & .168 & .124 & .994 & .597 & .467 \\
\hline \multirow{2}{*}{ Marital status } & Single & $15.7 \pm 3.4$ & $10.2 \pm 2.6$ & $6.4 \pm 1.9$ & $6.2 \pm 1.8$ & $10.0 \pm 3.1$ & $13.5 \pm 3.7$ & $10.4 \pm 2.9$ \\
\hline & Married & $14.9 \pm 4.5$ & $10.2 \pm 2.9$ & $6.6 \pm 1.5$ & $6.4 \pm 1.9$ & $9.4 \pm 2.7$ & $12.1 \pm 2.8$ & $10.2 \pm 2.1$ \\
\hline$p$ value & & .052 & .301 & .317 & .998 & .441 & .082 & .029 \\
\hline \multirow{2}{*}{$\begin{array}{l}\text { Daily work } \\
\text { hours }\end{array}$} & 6-12 hrs. & $15.6 \pm 3.7$ & $10.1 \pm 2.7$ & $6.8 \pm 1.8$ & $6.3 \pm 1.9$ & $9.7 \pm 3.0$ & $13.5 \pm 3.3$ & $10.6 \pm 2.6$ \\
\hline & $12-18$ hrs. & $15.6 \pm 3.5$ & $10.4 \pm 2.6$ & $5.8 \pm 1.6$ & $6.2 \pm 1.8$ & $10.0 \pm 3.1$ & $12.8 \pm 3.9$ & $10.0 \pm 3.1$ \\
\hline$p$ value & & .772 & .790 & .266 & .836 & .677 & .534 & .110 \\
\hline \multirow{2}{*}{ Private work } & Yes & $15.6 \pm 3.5$ & $10.3 \pm 2.7$ & $5.8 \pm 1.6$ & $6.3 \pm 1.8$ & $10.0 \pm 3.2$ & $12.8 \pm 3.9$ & $10.0 \pm 3.1$ \\
\hline & No & $15.6 \pm 3.7$ & $10.2 \pm 2.7$ & $6.8 \pm 1.8$ & $6.2 \pm 1.9$ & $9.8 \pm 3.0$ & $13.5 \pm 3.3$ & $10.6 \pm 2.6$ \\
\hline$p$ value & & .772 & .932 & .266 & .620 & .502 & .619 & .110 \\
\hline \multirow{3}{*}{$\begin{array}{l}\text { ICU } \\
\text { experience }\end{array}$} & $1-2 \mathrm{~m}$. & $15.5 \pm 3.8$ & $10.2 \pm 3.0$ & $6.8 \pm 1.8$ & $6.3 \pm 2.2$ & $9.6 \pm 3.7$ & $12.3 \pm 3.9$ & $10.2 \pm 3.2$ \\
\hline & 3-4 m. & $15.5 \pm 3.6$ & $10.4 \pm 2.6$ & $6.1 \pm 1.8$ & $6.1 \pm 1.7$ & $9.7 \pm 2.7$ & $13.5 \pm 3.5$ & $10.2 \pm 2.8$ \\
\hline & 5-6 m. & $15.9 \pm 3.6$ & $9.8 \pm 2.2$ & $6.6 \pm 1.7$ & $6.7 \pm 1.7$ & $10.5 \pm 3.0$ & $13.6 \pm 3.2$ & $11.0 \pm 2.2$ \\
\hline$p$ value & & .912 & .691 & .221 & .423 & .549 & .289 & .556 \\
\hline
\end{tabular}

\section{Discussion}

The first six months of employment are the most stressful for nurses. ${ }^{[26,27]}$ However, research on stress novice nurses, including nurses working in ICUs, experience in this critical area is extremely limited. Therefore, the current study aimed to assess occupational stress and stressors experienced by the newly practicing nurses in ICUs. The novelty of the current study is not only being among the first studies to examine occupational stress among Egyptian nurses using a standardized internationally accepted instrument (i.e., NSS) but also the examination of such phenomena in different stages of nurses' experience. Therefore, the results of the current study provide an insight on the chronological change of stress level and stressors among novice nurses. Up to our knowledge, there is no available Arabic version of the NSS validated in the Egyptian context. Use of the English version of the NSS in the current study was not problematic because nurse students in faculties of nursing in Egypt are educated in English. This adds to the strength of the current study in regard comparison with international studies.

The results of the current study depict that all studied nurses are experiencing either moderate or severe stress. A larger percent of nurses who have severe stress are females, single, working from 6 to 12 hours daily, and do not have private work. These findings may be attributed to that females play multiple roles beyond their work and may expose to multiple stressors from multiple sources. Males in the Egyptian culture rarely report their stress. Nurses who are single, working from 6 to 12 hours daily, and those who do not have not private work may have a plenty of time and may be concerned a lot about their work and its related stressors. The results of the current study also reveal that the number of nurses suffering severe stress increases with the increase of the experience. These findings may be attributed to that nurses are suffering stress from the beginning of their experience in ICU, but this stress is neither expressed nor managed, so it may accumulate and increase in severity with the increase in work experience.

Different studies reported different results regarding levels of nurses' perceived stress. Kamal et al. ${ }^{[19]}$ and Chang et al. ${ }^{[33]}$ reported that new nurse graduates perceived moderate job stress. Dagget and colleagues ${ }^{[17]}$ documented that $33.4 \%$, $34 \%$, and $32.7 \%$ of nurses had low, moderate and high stress, respectively. Hezaveh et al. ${ }^{[34]}$ reported that nurses experienced high levels of stress during the first months of their work and $52 \%$ of the studied nurses had severe level of stress. 
Mohamedkheir et al. ${ }^{[35]}$ documented that most of nurses experienced high level of occupational stress and that nurses' working experience had a significant effect on the overall nurses' stress level. Saini et al. ${ }^{[36]}$ reported that most of ICU nurses experienced moderate level of stress and that there was no significant relationship between stress level and nurses' gender, marital status, or experience. Another study ${ }^{[37]}$ found that nurses who had a longer ICU work experience had a lesser level of stress; this was attributed to that nurses at the professional level master competencies and have an appropriate situation controlling skills specially the critical ones.

Concerning the overall ranking of stressors, the results of the current study reveal that death and dying, increased workload, and inadequate preparation are the top three ranked stressors. Death and dying as a top stressor may be attributed to that during the beginning of clinical experience in ICU, nurses may have lack of self-confidence and may consider death as a poor outcome attributed to a failure of management and control over patients' deterioration. In addition, they have difficulty with effective prioritization of management tasks, so they feel overloaded. The results of the current study also revealed that the least ranked stressor is conflict with other nurses. This may be due to that beginner nurses during the first months of experience are lacking clinical experience and may forget the underpinning scientific knowledge, so they are in an urgent need for ICU senior staff guidance and support and are obeying senior colleagues' instruction without conflict. Our result is in line with Milutinovic et al., ${ }^{[5]} \mathrm{Mo}-$ hamedkheir et al. ${ }^{[35]}$ and Sarafis et al. ${ }^{[14]}$ who reported that death and dying was considered the most stressful situations. Yet, some other studies ${ }^{[37,38]}$ reported nursing work conditions and lack of knowledgeable nurses as the most stressing factors. Such discrepancies may be due to the contextual difference among different countries particularly, nurses' educational preparation, pre- and in-service training, and type of patients of whom newly practicing nurses are caring.

The results of the current study also reveal a difference in the stressors experienced by newly practicing nurses based on the length of their experience. Death and dying is one of the top ranked stressors at different length of experiences. The workload is one of the top ranked stressors starting from the third to the six months of experience. This may be due to that ICU staff may have unrealistic expectations and assume that intern nurses gained adequate experience after 2 months of practice in ICU, so they leave them fully responsible about more than one patient per time without any assistance because of the marked shortage of nursing staff. Inadequate preparation is the top stressor for nurses in the first two months of experience in ICU. This may be attributed to that this period is the beginning of the transition period from nurse student to practicing nurse. They were shielded during the study period from total responsibility of patients and managing the whole situation within a highly technological environment. In addition, they are not exposed to clinical challenges occur during sudden crisis.

\section{Limitations}

This study was conducted only at four ICUs and other ICUs were not included. The small sample size and selecting participants on convenience is another limitation made the results of this study cannot be generalized.

\section{Conclusions}

It can be concluded from this study that newly practicing nurses in ICUs face a significant level of stress. Death and dying, workload, and inadequate preparation are the top ranked stressors.

\section{Recommendations}

New practicing nurses in ICU need to be trained through a stress-management program. The topic of death and dying in ICU is highly needed to be embedded into nursing curriculum. Strategies to help graduate nurses cope with workload might have a positive effect on the nurses' perceived experience. Further research recruiting a larger sample size from multiple units may allow performing more advanced statistical analyses such as multilevel regression models so as to deeply explore individual and organizational factors associated with nurses' perceived stress.

\section{ACKNOWLEDGEMENTS}

The authors would like to acknowledge nurses for participation in this study.

\section{CONFlicts OF INTEREST Disclosure}

The authors declare that there is no conflict of interest.

\section{REFERENCES}

[1] Gray P, Anderson G. The nursing stress scale: development of an instrument. Journal of Behavioral Assessment. 1981; 3(1): 11-23. https://doi.org/10.1007/BF01321348
[2] Rashid I, Talib P. Occupational stress and coping styles among doctors: role of demographic and environmental variables. The Journal of Business Perspective. 2015; 19(3): 263-75. https: //doi.org/10.1177/0972262915599473 
[3] International Labour Organisation. Psychosocial factors at work: recognition and control-report of the joint ILO/WHO Committee on occupational health. Available from: http://www. who.int/occupational_health/publicatio ns/ILO_WHO_1984_report_of_the_joint_committee.pdf

[4] Richardson M, Rothstein R. Effects of occupational stress management intervention programs: a meta-analysis. Journal of Occupational Health Psychology. 2008; 13(1): 69-93. PMid:18211170 https://doi.org/10.1037/1076-8998.13.1.69

[5] Milutinovic D, et al. Professional stress and health among critical care nurses in Serbia. Arh Hig Rada Toksikol. 2012; 63(2): 171-80. PMid:22728799 https://doi.org/10.2478/10004-1 254-63-2012-2140

[6] Damit A. Identifying sources of stress and level of job satisfaction amongest registered nurses within the first three years of work as registerd nurse in Brinei Darussalam in school of nursing, Center for Health Research. Queensland University of Technology. 2007.

[7] Jannati Y, Mohammadi R, Seyedfatemi N. Iranian clinical nurses' coping strategies for job stress. Journal of Occupational Health. 2011; 35(2): 123-9. https://doi.org/10.1539/joh.010015

[8] Shivaprasad H. Work related stress of nurses. Journal of Psychiatric Nursing. 2013; 2(2): 53-58.

[9] Cavalheiro A, Moura-Junior D, Lopes A. Stress in nurses working in intensive care units. Rev Latino-am Enfermagem. 2008; 16(1): 29-35. https://doi.org/10.1590/S0104-11692008000100005

[10] Rush K, et al. Best practices of formal new graduate nurse transition programs: an integrative review. Int J Nurs Stud. 2013; 50(3): 345-56. PMid:22795800 https://doi.org/10.1016/j.ijnurstu. 201 2.06 .009

[11] Alfieri E, et al. Advanced competencies mapping of critical care nursing: a qualitative research in two Intensive Care Units. Acta bio-medica: Atenei Parmensis. 2017; 88(3-S): 67-74.

[12] EfCCNa. EfCCNa competencies for European critical care nurses. Available from: http://www. efccna.org/education/publica tions

[13] Clair M. New graduate nurses' experiences of transition during orientation into critical care. 2013, University of Wisconsin Milwaukee.

[14] Sarafis P, et al. The impact of occupational stress on nurses' caring behaviors and their health related quality of life. BMC Nursing. 2016; 15: 56. PMid:27708546 https://doi .org/10.1186/s12912-0 16-0178-y

[15] Colligan T, Higgins E. Workplace stress: etiology and consequences. Journal of Workplace Behavioral Health. 2006; 21(2): 89-97. https : //doi.org/10.1300/J490v21n02_07

[16] Wheeler H, Riding R. Occupational stress in general nurses and midwives. British Journal of Nursing. 1994; 3(10): 527-34. https : //doi.org/10.12968/bjon.1994.3.10.527

[17] Dagget T, Molla A, Belachew T. Job related stress among nurses working in Jimma Zone public hospitals, South West Ethiopia: a cross sectional study. BMC Nursing. 2016; 15: 39. PMid:27313502 https://doi.org/10.1186/s12912-016-0158-2

[18] Inoue K, Versa G, Matsuda L. Stress level among intensive care nurses in the municipality of Paraná (Brazil). Invest Educ Enferm. 2014; 32(1): 69-77. PMid:25229905

[19] Kamal S, et al. The effect of nurses' perceived job related stressors on job satisfaction in Taif governmental hospitals in Kingdom of Saudi Arabia. Journal of American Science. 2012; 8(3): 119-125.

[20] Yeh M, Yu S. Job stress and intention to quit in newly-graduated nurses during the first three months of work in Taiwan. Journal of Clinical Nursing. 2009; 18(24): 3450-60. PMid:20487491 https : //doi.org/10.1111/j.1365-2702.2009.02941.x
[21] Murphy F. Stress among nephrology nurses in Northern Ireland Nephrology Nurrsing Journal. 2004; 31(4): 423-31. PMid: 15453234

[22] Schoessler M, Waldo M. The First 18 Months in Practice: a developmental transition model for the newly graduated Nurse. Journal for Nurses in Staff Development. 2006; 22(2): 47-52. PMid:16603899 https : //doi .org/10.1097/00124645-200603000-00001

[23] Duchscher B. A Process of becoming: the stages of new nursing graduate professional role transition. J Contin Educ Nurs. 2008; 39(10): 441-50. https://doi .org/10.3928/00220124-20081001-03

[24] Missen K, McKenna L, Beauchamp A. Satisfaction of newly graduated nurses enrolled in transition-to-practice programmes in their first year of employment: a systematic review. J Adv Nurs. 2014; 70(11): 2419-33. PMid:24989716 https://doi.org/10.1111/ jan. 12464

[25] Eltaybani S, Mohamed N, Abdelwareth M. Nature of nursing errors and their contributing factors in intensive care units. Nursing in Critical Care. 2018.

[26] Charnley E. Occupational stress in the newly qualified staff nurse Nursing Standard. 1999; 13(29): 33-36. https ://doi .org/10.7 748/ns.13.29.33.s55

[27] O'Shea M, Kelly B. The lived experiences of newly qualified nurses on clinical placement during the first six months following registration in the Republic of Ireland. Journal of Clinical Nursing. 2007; 16(8): 1534-42. PMid:17655542 https://doi.org/10.1111/j. 1365-2702.2006.01794.x

[28] Sönmez B, Yıldırım A. Difficulties experienced by newly-graduated nurses in Turkey: a qualitative study of the first six months of employment. Journal of Nursing Education and Practice. 2016; 6(1): 104-110. https://doi.org/10.5430/jnep.v6n1p104

[29] Healy M, Reed C. Report on the transition to practice needs of newly graduated enrolled nurses and postgraduate (entry to practice) midwives. Available from: http://www.health.vic.gov.au/ _-_data/assets/pdf_file/0003/911748/Transition-to-P ractice_Final-report_March_2015.pdf

[30] NSI. National Healthcare Retention \& RN Staffing Report 2016. Available from: https://avanthealthcare.com/pdf/Nation alHealthcareRNRetentionReport2016.pdf

[31] Jose T, Bhat M. A descriptive study on stress and coping of nurses working in selected hospitals of Udupi and Mangalore districts Karnataka, India. IOSR Journal of Nursing and Health Science. 2013; 3(1): 10-18. https://doi .org/10.9790/1959-03111018

[32] Cadmus E. Conflict management style, supportive work environments and the experience of work stress in emergency nurses. Journal of Nursing Management. 2016; 24(2): 211-8. https ://doi.org/ 10.1111/jonm. 12302

[33] Chang E, Hancock K. Role stress and role ambiguity in new nursing graduates in Australia. Nursing and Health Sciences. 2003; 5: 155-63. https://doi.org/10.1046/j.1442-2018.2003.00147.x

[34] Hezaveh $M$, et al. The experience of stress among new clinical nurses. Nurs Pract Today. 2014; 1(4): 199-206.

[35] Mohamedkheir R, et al. Occupational stress among nurses working in intensive care units in public hospitals of Khartoum State, Sudan. American Journal of Health Research. 2016; 4(6): 166. https://doi.org/10.11648/j.ajhr. 20160406.13

[36] Saini R, Kaur S, Das K. Assessment of stress and burnout among intensive care nurses at a tertiary care hospital. Journal of Mental Health and Human Behaviour. 2011; 16(1): 43-8.

[37] Monte $\mathrm{P}$, et al. Stress among professional nurses working in intensive care units. Acta Paul Enferm. 2013; 26(5): 421-7.

[38] Moola S, Ehlers V, Hattingh S. Critical care nurses' perceptions of stress and stress-related situations in the workplace. Curationis. 2008; 31(2): 74-83. 